\title{
ASPECTOS NUTRICIONAIS DA BOVINOCULTURA LEITEIRA DO MUNICÍPIO DE IRITUIA-PA
}

\author{
COUTINHO, Pablo Wenderson Ribeiro ${ }^{1}$ \\ GALDINO, Iza Layana Cezário ${ }^{2}$ \\ MOTA, Adriano Vitti ${ }^{3}$
}

ISSUE DOI: $10.3738 / 1982.2278 .1064$

\begin{abstract}
RESUMO: A exigência diária em nutrientes e energia pelo animal é determinada pelo nível de produção, peso corporal, estádio fisiológico e pela interação com o ambiente. Em sistemas de manejo voltados a maximizar a produção dos animais, vacas em lactação necessitam de alimento em quantidade e qualidade para que atinjam os desafios fisiológicos a que são submetidas, para obtenção de índices zootécnicos satisfatórios. O objetivo deste trabalho foi caracterizar a nutrição dos bovinos leiteiros do município de Irituia, bem como avaliar o perfil dos pecuaristas da região. Onde foi realizado um diagnóstico partitivo e analise qualitativa da produção leiteira do município. Os produtores do polo leiteiro apresentaram resultados relevantes em suas produções apesar de todas as limitações encontradas e rusticidade técnica no qual suas produções se encontram.
\end{abstract}

Palavras-chave: Pecuaristas. Bacia leiteira. Pastagens.

\section{NUTRITIONAL ASPECTS OF DAIRY CATTLE IN THE MUNICIPALITY OF IRITUIA-PA}

SUMMARY: The daily requirement of nutrients and energy for the animal is determined by the level of production, body weight, physiological state and the interaction with the environment. In management systems aimed at maximizing production of animals, milking cows need food in quantity and quality to meet the physiological challenges that are subject to obtaining satisfactory indexes. The aim of this study was to characterize the nutrition of dairy cattle in the municipality of Irituia and evaluate the profile of the region's pastoralists. Where a diagnosis was made partitive and qualitative analysis of milk production in the municipality. Polo dairy producers showed significant results in their production despite all the limitations found rusticity and its production technique in which they find themselves.

Keywords: Ranchers. Basin dairy. Pastures.

\section{INTRODUÇÃO}

Os avanços alcançados pela ciência no campo da nutrição e alimentação dos animais ruminantes, principalmente nas últimas duas décadas, foram consideráveis, observaram-se avanços na capacidade produtiva dos animais, fato que ampliou os desafios no campo da nutrição, tendo em vista que tratar-se de elevadas exigências nutricionais. A produção leiteira caracteriza-se por grandes demandas fisiológicas de alimento em quantidade e qualidade, mas

\footnotetext{
${ }^{1}$ Engenheiro Agrônomo pela Universidade Federal Rural da Amazônia, estudante de Mestrado em Agronomia pela Universidade Estadual do Oeste do Paraná

${ }^{2}$ Engenheira Agrônoma pela Universidade Federal Rural da Amazônia

${ }^{3}$ Professor da Universidade Federal Rural da Amazônia Campus Capitão Poço
} 
existe a necessidade de que todos os recursos disponíveis na propriedade sejam consumidos de forma eficiente, para um maior aproveitamento dos recursos disponíveis e diminuir custos na produção leiteira.

Dados recentes da FAO (2010) mostram que o Brasil possui o segundo maior rebanho leiteiro do mundo com média de 22 milhões de cabeças e é o quinto maior País produtor de leite com média aproximada de 29 bilhões de litros/ano, porém nossa produtividade é baixa, devidos aos baixos índices zootécnicos e a má utilização das pastagens, o que nos deixa em $19^{\circ}$ colocado no ranque mundial, conferindo ao nosso País 3\% de presença no mercado Global.

Na Região Norte, uma das principais características dos sistemas leiteiros desenvolvidos, é a baixa produtividade média por vaca, em torno de 4-5 litros por dia, historicamente atribuída à alimentação deficiente das vacas, em termos de quantidade e qualidade (SIMÃO NETO, et al. 1989) e ao baixo padrão genético do rebanho (TOURRAND et al. 1998), além dos baixos índices zootécnicos.

Os solos da região nordeste paraense apresentam acidez elevada, baixa capacidade de troca de cátions, deficiência de $\mathrm{N}, \mathrm{P}, \mathrm{K}, \mathrm{S}, \mathrm{Ca}, \mathrm{Mg}, \mathrm{B}, \mathrm{Cu}, \mathrm{Zn}$. O elemento considerado mais crítico é o fósforo, embora outros macroelementos como nitrogênio, potássio e cálcio podem também faltar, principalmente em sistemas mais intensivos de utilização de pastagem (VEIGA, 1995). Esses que associadas ao manejo inadequado das pastagens levam a baixa produtividade e qualidade das pastagens (BENDAHAN; VEIGA, 2002).

A utilização de pastagens por rebanhos leiteiros pode reduzir os custos de produção de leite, principalmente pela redução nos dispêndios com alimentos concentrados, com combustíveis e com mão de obra (HOFFMAN et al., 1993; VILELA et al.,1996; FONTANELI, 1999; MULLER et al., 1995).

Segundo Gomide (1994), a aptidão leiteira da vaca, o valor nutritivo do pasto e o consumo de forragem determinam a produção de leite da vaca. Sob pastejo, o consumo de matéria verde é afetado principalmente pela disponibilidade de forragem, mas também pela estrutura da vegetação, densidade, altura e relação. O objetivo do trabalho foi caracterizar a nutrição dos bovinos leiteiros do município de Irituia, bem como avaliar o perfil dos pecuaristas da região.

\section{MATERIAL E MÉTODO}

O trabalho foi realizado no município de Irituia - PA que pertence à microrregião do Alto Rio Guamá, nordeste paraense, no período de janeiro a dezembro de 2012, pelo Programa de 
Desenvolvimento Sustentável da Pecuária Leiteira do Alto Rio Guamá - financiada com Recursos do PROEXT- 2011.

Inicialmente foi realizado pré - diagnostico com dados obtidos junto a EMATER-PA e a Secretaria de Agricultura do munícipio de Irituia onde foi levantada informações sobre a bacia leiteira da região: tamanho, número de produtores, produtividade média, nomes dos produtores e comunidades aonde residem. A obtenção dessas informações tinha como finalidade a caracterização do universo em que se pretendia trabalhar.

De posse dessas informações foram realizadas visitas a cada um dos produtores onde foi realizado diagnostico através de entrevista semiestruturada para levantamento das características socioeconômico e produtivas da atividade.

Os 61 questionários aplicados nas entrevistas eram compostos por questões específicas que pretendiam alcançar as variáveis chave para a elaboração deste trabalho. Os dados obtidos foram plotados e processados através do programa Microsoft Office Excel 2007 (, onde foram obtidas as médias e desvios padrões para cada uma das características aferidas.

\section{RESULTADO E DISCUSSÃO}

De acordo com dados adquiridos junto aos produtores, foi possível observar que os produtores possuem idade média de $43 \pm 11,4$ anos, com renda familiar média de $\mathrm{R} \$ 1.970,00 \pm$ 2.813,49 mês. Os produtores em sua maioria adquiriram sua propriedade de seus familiares, iniciando na atividade pecuária, ainda jovem.

Foram observados os seguintes parâmetros no perfil dos pecuaristas do município de Irituia. Com relação ao nível de escolaridade, a percentagem de produtores com nível fundamental incompleto foi de $72 \%, 11 \%$ possuem nível médio incompleto, $8 \%$ são analfabetos e $2 \%$ possuem nível superior, diante da pesquisa não se contatou nenhum produtor com nível médio completo. A falta de oportunidade e a necessidade em ajudar na renda familiar, faz com que as pessoas não continuem os estudos.

Observando os dados de quantidade de mão de obra externa empregada e remuneração mensal da atividade, pode se notar que a produção de leite no município de Irituia é predominantemente familiar, sendo este resultado superior aos resultados encontrados por Zoccal et al. (2004).

Outro fator avaliado na pesquisa foi à percentagem das pessoas que recebem algum financiamento, que possibilita ao produtor recursos para sua produção, dentre os entrevistados $37 \%$ responderam que recebem financiamento, como PRONAF (Programa Nacional de Fortalecimento da Agricultura Familiar). O programa possui as mais baixas taxas de juros dos 
financiamentos rurais, além das menores taxas de inadimplência entre os sistemas de crédito do País, é justamente devido a esses programas, que muitos agricultores do município em questão decidiram modificar sua atividade principal, que antes era de corte e passou para a atividade leiteira.

O acesso a todas as propriedades são realizados através de estradas não asfaltadas. Estradas estas que possuem melhorias progressivas, haja visto que $80 \%$ dos produtores às classificam de boa a regular, fato não observado pelos extensionistas, que se deslocaram até as propriedades e pela baixa velocidade deslocamento na mesma com velocidade média aproximada de $32 \mathrm{Km} / \mathrm{h}$, devido a má qualidade da via e precariedade das pontes. O que nos leva a crer que a percepção da qualidade das vias não esta ligada a qualidade da mesma, e sim a comparação com a qualidade da mesma em momentos anteriores.

É perceptível que a qualidade da pastagem dos produtores do município de Irituia- PA encontra se em parâmetros positivos, com 47,5\% bom (Tabela 1), aonde ele vem a classificar suas pastagens de boa a regular o que vem a proporcionar um sucesso na produção de leite quando possuem um pasto de boa qualidade, possibilitando aos mesmos uma produção média de leite de 5,42 litros/vaca/dia acima da produtividade nacional de 4,9 litros/vacas/dia e acima dos valores estaduais onde o Pará possui uma média em torno de torno de 4-5 litros por dia.

Tabela 1 - Perspectivas dos produtores de leite do município de Irituia sobre a qualidade de suas pastagens no município de Irituia/PA.

\begin{tabular}{lllcll}
\hline \multicolumn{2}{l}{ Qualidade das pastagens } & \multicolumn{2}{c}{ Utilização de adubação } & \multicolumn{2}{c}{ Limpeza de pastagens } \\
\hline Bom & Regular & Ruim & & Manual & Mecanizado \\
$47,5 \%$ & $45,9 \%$ & $6,5 \%$ & $50 \%$ & $96,7 \%$ & $3,3 \%$ \\
\hline
\end{tabular}

De acordo com informações do Anualpec (2010), 90\% do leite produzido no Brasil é de sistemas em pastagem e as gramíneas representam $85 \%$ de alimento volumoso consumido pelos animais. Nesse sentido, deve-se propiciar às plantas forrageiras que compõem a pastagem um ambiente adequado para seu desenvolvimento visando também em atender as demandas de exigências do rebanho, para que os esforços e ações empregados resultem em produções de leite adequadas.

O plantio da pastagem é uma etapa primordial para o processo de uma boa formação do pasto, com isso são várias as técnicas adotadas para exercer tal pratica. Como os produtores dessa região são provenientes de pequenos e médios produtores a carência de mecanização na região é bastante notável, sobretudo pela falta de recursos, este fator é bem claro quando observamos os 
valores mensurados na tabela 2 onde $66,6 \%$ dos produtores utilizam a plantadeira manual, pois é um recurso que esta mais próxima ao seu alcance e sua realidade.

Tabela 2 - Manejo de pastagens utilizados pelos produtores de leite do município de Irituia/PA.

\begin{tabular}{|c|c|c|c|c|c|c|c|}
\hline \multicolumn{4}{|c|}{ Tipo de plantio } & \multicolumn{4}{|c|}{ Forrageiras predominantes } \\
\hline $\begin{array}{c}\text { Manual } \\
\text { a lanço }\end{array}$ & $\begin{array}{c}\text { Plantadeira } \\
\text { manual }\end{array}$ & $\begin{array}{l}\text { Plantadeira } \\
\text { manual e } \\
\text { mecanizada }\end{array}$ & $\begin{array}{l}\text { Exclusivamente } \\
\text { Mecanizado }\end{array}$ & 1 & 2 & 3 & 4 \\
\hline $6,6 \%$ & $66,6 \%$ & $5 \%$ & $20 \%$ & $70 \%$ & $7 \%$ & $15 \%$ & $8 \%$ \\
\hline
\end{tabular}

Em sistemas extensivos, normalmente o solo não é adubado na formação da pastagem, principalmente quando a área passou por um pousio e recuperou parcialmente a sua fertilidade. Porém, na região o sistema utilizado e o intensivo, onde é recomendada pelo menos a adubação fosfatada, na base de 30 a $60 \mathrm{~kg}$ de $\mathrm{P}_{2} \mathrm{O}_{5} /$ ha (EMBRAPA, 2005). Adicionalmente, cálcio e magnésio podem ser adicionados via $500 \mathrm{~kg}$ de calcário dolomítico/ha (EMBRAPA, 2005). Adubação tem uma importância notória para a pastagem, pois ela disponibiliza os nutrientes necessários que não se faz presente no solo naturalmente para planta, onde de $100 \%$ dos produtores mostra que 50\% (Tabela 1) fazem o uso da adubação em sua pastagem para com isso beneficiar sua criação.

Umas das vantagens da adubação é disponibilizar uma melhor nutrição para planta, na qual esta será um dos principais alimentos para o animal, sabendo que a exigência diária em nutrientes e energia pelo animal é determinada pelo nível de produção, peso corporal, estádio fisiológico e pela interação com o ambiente (ambiente climático, instalações e equipamentos, manejo, tipo de alimento, etc.).

Em sistemas de manejo voltados a maximizar a produção dos animais, vacas em lactação necessitam de alimento em quantidade e qualidade para que atinjam os desafios fisiológicos a que são submetidas, para obtenção de índices zootécnicos satisfatórios. Animais em lactação necessitam de alimentação com adequadas exigências metabólicas de diversas funções simultâneas (lactação, gestação e mantença) em vacas; em novilhas e vacas de primeira cria soma-se a esta demanda as necessidade de crescimento do animal e em conformidade com a fase em que se encontrão.

Após esses processos de formação e necessário os processos que levam a manutenção do pasto, a limpeza é uma delas, apesar de uma técnica simples é muito importante para manutenção e integridade do pasto consiste na limpeza da área visando controlar a incidência de plantas daninhas que causam vários danos as forrageiras entre eles a competitividade. $\mathrm{O}$ procedimento 
utilizado na região pelos produtores ainda é o manual, onde 96,7\% faz uso dessa técnica (Tabela 1), isso de dar principalmente pelo porte dos produtores serem de pequenos e médios produtores e a carência de mecanização na região é bastante notável, sobretudo pela falta de recursos.

O padrão de uso da terra dos produtores familiares em início de pecuarização se baseia no processo sucessivo de derruba e queima da floresta secundária (capoeira) para plantio de culturas anuais, principalmente a mandioca, e pequenas parcelas de culturas perenes e pastagem. As espécies forrageiras predominantes são Quicuio (Brachiaria humidicola) e Braquiarão (B. brizantha cv Marandú), gramíneas forrageiras tolerantes a solos ácidos e de baixa fertilidade. O rebanho geralmente é pequeno, algumas vezes funcionando como reserva de capital e os bovinos são mestiços de várias raças (SIEGMUND-SCHULTZE et al., 2007).

Na região do polo leiteiro, não só a preferência como também a predominância são das cultivares do gênero Brachiaria assim contestada na tabela 2. Onde tem sido muito utilizada em função das suas características, como tolerância à restrição na fertilidade do solo, resistência à cigarrinha das pastagens, elevada produtividade quando devidamente adubada e manejada (ANDRADE, 2003), embora o seu valor nutritivo seja relativamente baixo. O tempo de formação gira em torno de 90 a 120 dias após germinação e o primeiro pastoreio deve ser feito aos de 90 dias com gado leve (boi magro, garrotes), no momento da entrada dos animais, a pastagem apresenta altura em torno de $1,0 \mathrm{~m}$, devendo o gado ser retirado quando a mesma chegar a $30 \mathrm{~cm}$ do solo. Tais características que são adeptas a região, o que explica a opção dos produtores na utilização da cultivar.

O uso de cultivares consorciada esta em segundo lugar na tabela 2 apesar de ser uma pequena porcentagem de $15 \%$, essa técnica é utilizada por alguns dos produtores da região. Foi observado que o motivo principal dos produtores a adotar esse tipo de cultivo e fornecer uma diversidade maior ao rebanho de proteína bruto, bem como proporcionar consorciação de culturas que entrem em sinergias no quesito patabilidade.

As vantagens de se utilizar pastagem, como fonte principal de volumoso na alimentação animal, estão diretamente relacionadas com diminuição de custo de produção, que representa 70\% de Brachiaria Brizanta cv Marandú, dentro do sistema. Os animais passam a ser a ferramenta que cortará a gramínea, através do pastejo, o que vem a proporcionar ao animal selecionar folhas, que é a parte da planta mais nutritiva, reduzindo despesas com alimentos concentrados, combustíveis, mão de obra e instalações, especialmente aquelas destinadas ao abrigo de animais e maquinário.

O processo de fornecimento de sal mineral ao gado tem o papel principal de fornecer uma suplementação, ao qual o pasto não vem a suprir todas as exigências minerais que os animais 
possuem. É bem diversificada a utilização de sal mineral no município como mostra a Tabela 3, porém com uso maior de sal mineral branco de 47,3\%, o que chega a ser um uso inadequado, pela utilização apenas do sal branco sem nenhum elemento protéico, que vem a ser um custo a mais no processo sem nenhum benefício. Assim como os cuidados com o pasto e a utilização de um sal mineral para com um meio de suplementação é necessário que se atente ao conforto animal ou conforto térmico com isso foram observados que $100 \%$ dos produtores são cientes de que o sombreamento trás benefícios ao animal, por isso, possuem alguma área sombreada nas suas propriedades.

Tabela 3 - Perspectivas dos produtores de leite do município de Irituia sobre alimentação dos bovinos leiteiros no município de Irituia/PA.

\begin{tabular}{ccccc}
\hline Alimentação & Áreas de sombra & \multicolumn{3}{c}{ Suplementação mineral } \\
\cline { 3 - 5 } $\begin{array}{c}\text { exclusive } \\
\text { pasto }\end{array}$ & nas pastagens & Sal Comum & Sal Mineral & $\begin{array}{c}\text { Comum + } \\
\text { Mineral }\end{array}$ \\
$88,3 \%$ & $100 \%$ & $6,6 \%$ & & $50 \%$ \\
\hline
\end{tabular}

O sombreamento adéqua ao animal às condições de conforto térmico, onde em condições de estresse causado pelas altas temperaturas ele tende a ter um maior gasto de energia, pois ele se movimentará mais a procura de sombra, no qual poderia esta utilizando deste tempo para pastejar e ruminar, o que acarretara redução de produtividade do animal.

Na tabela 4 mostra a área média por piquete de todas as propriedades da região, onde pode se observar que a área de 10 ha por piquete e mais utilizada pra propriedades de pequena, média e grandes extensões.

Tabela 4 - Área e tempo médio por piquete, utilizado pelos produtores de leite do município de Irituia/PA.

\begin{tabular}{|c|c|c|c|c|c|}
\hline \multicolumn{4}{|c|}{ Área média por piquete } & \multicolumn{2}{|c|}{ Tempo médio por piquete } \\
\hline 1 ha & $3 \%$ & 12 ha & $9 \%$ & 5 a 10 dias & $11,6 \%$ \\
\hline 4 ha & $8 \%$ & 13 ha & $2 \%$ & 15 a 20 dias & $35,0 \%$ \\
\hline 5 ha & $3 \%$ & 15 ha & $15 \%$ & 25 a 30 dias & $38,3 \%$ \\
\hline 6 ha & $3 \%$ & 20 ha & $15 \%$ & 2 meses & $5,0 \%$ \\
\hline 7 ha & $3 \%$ & 21 ha & $3 \%$ & 3 meses & $3,3 \%$ \\
\hline 8 ha & $3 \%$ & 44 ha & $2 \%$ & 4 meses & $3,3 \%$ \\
\hline 9 ha & $5 \%$ & 50 ha & $2 \%$ & 6 meses & $3,3 \%$ \\
\hline 10 ha & $22 \%$ & 60 ha & $2 \%$ & & \\
\hline
\end{tabular}


O manejo do tempo de pastejo pode ser caracterizado com o controle das relações do sistema solo planta e animal. O solo é base do sistema e atua como fonte de nutrientes para pastagens, a planta é a fonte de nutrientes para o animal e atua como modificador das condições físicas e químicas do solo, o animal atua como modificador das condições do solo e da planta.

O tempo que o animal passa em cada piquete altera fatores na integridade do pasto bem como seu tempo de rebrota da forrageira, como altos índices de compactação do solo causado principalmente por altas taxas de lotação do animal no solo. Mas Podemos observar que 38,8\% dos produtores (Tabela 4) da região possuem um período de utilização de tempo médio em cada piquete de 25 a 30 dias.

O solo é a base do sistema que atua como um dos principais fornecedores de nutrientes para o pasto. Todavia a degradação e compactação causada pela pecuária e relativamente alta, por isso a importância do período de descanso e pastoreio do animal a cada piquete tendo em vista diminuir os impactos causados pelo os mesmo.

\section{CONCLUSÃO}

Tendo em vista que a missão do produtor de leite é fazer de sua profissão uma atividade economia, seu foco principal deve ser o aumento do lucro e não o aumento da produção individual de suas vacas. Isso é possível com a devida otimização da produção de leite da propriedade, com a utilização de seus próprios recursos, com ênfase no manejo e fertilidade dos solos dedicados a produção de forragem.

\section{REFERÊNCIAS}

ANDRADE, F. M. E. Produção de forragem e valor alimentício de capim marandu submetido a regimes de lotação continua por bovino de corte. 2003.125p.Dissertação (Mestrado em agronomia) - Escola Superior de Agricultura Luiz de Queiroz, Universidade de São Paulo, Piracicaba.

ANUALPEC. 2010. Anuário da Pecuária Brasileira. FNP Consultoria e Agroinformativos, São Paulo, SP. 400pp.

BENDAHAN, A. B.; VEIGA, J. B. da. Relação entre as características do solo e da pastagens na microrregião de Castanhal, Pará. Belém, PA: Embrapa Amazônia Oriental, 2002. 16 p. (Embrapa Amazônia Oriental. Boletim de Pesquisa, 4). 
EMBRAPA - EMPRESA BRASILEIRA DE PESQUISA AGROPECÚARIA . Centro Nacional de Pesquisa de Solos. Sistema brasileiro de classificação de solos. 3.ed. Rio de Janeiro, 2005. 306p.

FAO (2010) FAO/ World Foods: Tabla de producción mundial de alimentos. Disponível em <http://www.faostat.fao/faostat/collection?subset=agriculture>. Acesso em 08/03/2010.

FONTANELI, R. S. Forage systems for year-round grazing by lactating dairy cows. Gainesville: University of Florida, 1999. 220p. Ph.D. Dissertation.

GOMIDE, J. A. Manejo de pastagens para a produção de leite. In: SIMPÓSIO

INTERNACIONAL DE FORRAGICULTURA. Reunião da Sociedade Brasileira de Zootecnia, 31. Maringá-Pr. 1994. Anais...Maringá:Pr. EDUEM, 1994, p. 141-168

HOFFMAN, K.et al. Quality evaluation and concentrate supplementation of ratational pasture grazed by lactating cows. Journal of Dairy Science, v. 76, p. 2651-2663. 1993.

MULLER, L. D.; KOLVER, E. S.; HOLDEN, L. A. Nutritional needs of high producing cows on pasture. CORNELL NUTRITION CONFERENCE FOR FEED MANUFACTURERS, Proceeding..., 1995, Rochester, p. 106-120. 1995.

SIEGMUND-SCHULTZE, M.; RISCHKOWSKY, B.; VEIGA, J.B.; KING, J.M. Cattle are cash generating assets for mixed smallholder farms in the Eastern Amazon. Agricultural Systems, v. 94, 738-749, 2007.

SIMÃO NETO, M.et al. Características dos sistemas de produção de leite da região Bragantina. Belém, PA: Embrapa-CPATU, 1989. 48 p. (Embrapa-CPATU. Documentos, 9)

TOURRAND, J. F.et al. Produção leiteira em área de fronteira agrícola da Amazônia: o caso do município de Uruará (PA), na Transamazônica. In: HOMMA, A. K. O. (Ed.). Amazônia: meio ambiente e desenvolvimento agrícola. Brasília, DF: Embrapa-SPI; Belém: Embrapa-CPATU, 1998. p. 345-365.

VEIGA, J. B. da. Rehabilitation of degraded pasture areas. In: SIMPÓSIO SOBRE MANAGEMENT AND REHABILITATION OF DEGRADED LANDS AND SECONDARY FORESTS IN AMAZONIA, 1993, Santarém, PA. Proceedings.... Rio Piedras: IITF : USDA, 1995. p. 193-202.

VILELA, D.et al. Produção de leite de vacas Holandesas em confinamento ou em pastagem de coast-cross. Revista Brasileira de Zootecnia, v. 25, p. 1228-1244. 1996. 
